\title{
The Influence of Learning Style on Learning Attitude with Multimedia Teaching Materials
}

\author{
Fumei Weng ${ }^{1 *}$, Hann-Jang Ho ${ }^{1}$, Rong-Jou Yang ${ }^{2}$, Chin-Hui Weng ${ }^{3}$ \\ ${ }^{1}$ WuFeng University, TAIWAN \\ ${ }^{2}$ University of Texas at EI Paso, TX, USA \\ ${ }^{3}$ Peikang Junior High School, TAIWAN
}

Received 11 September 2017 - Revised 11 May 2018 • Accepted 20 June 2018

\begin{abstract}
The aim of this study is to discover the influence of multimedia materials of Taekwondo Aerobic on students' learning attitude with diverse learning styles. Taekwondo Aerobic class is a new subject for junior high school teachers in Taiwan. The junior high school students are promoted to learn this activity to improve their health. With the advance of digital technology, multimedia-based teaching style has been emphasized and applied. Not every student handles the material well and their learning styles also influence their learning achievement. Participants were students on grade seventh and eighth. Students are divided into two groups, with one experiment group adopting multimedia-based teaching, and one control group adopting traditional teaching respectively. Students are given questionnaires after the experiment. There were 101 valid questionnaires. The results show that adopting multimedia-based teaching style promotes students' learning attitude. Using multimedia-based teaching style has significant effects on students' learning attitude with different learning styles in teaching Taekwondo Aerobic.
\end{abstract}

Keywords: multimedia materials, taekwondo aerobic, learning attitude, learning style

\section{INTRODUCTION}

Physical education in school is an important way to mold and educate students of talent in the robust development of body and mind and a foundation to promote the stamina of nationals. A project titled Athletics Population Doubly Increased Project was planned by the authority of Yunlin county. It was aimed at population with no athletics. It also intended to enable them with athletics so as to essentially increase the population with a regular pattern of athletics.

In order to promote both the healthy physical fitness of students of elementary and junior high schools and the existing martial arts athletics, county government of Yunlin in 1991 furthered a project - Seed Instructors Training for Spreading Martial Arts Athletics of Entire People of Community. This project selected the seed instructors propagated the martial arts athletics from the elementary and junior high schools. These instructors convey the quintessence of national culture. Every public and private elementary school and junior high school need to stipulate a teacher to participate in the training of martial arts athletics in this project. They facilitate the spreading and yearly evaluation of the athletics.

Taekwondo Aerobic based on Taekwondo consisting of quality, strength, and a set pattern. There was a dancing song fitting in with the dynamism of music. The song was edited and produced by professional Taekwondo athletics coach who was hired by The Committee of Taekwondo, Yunlin. The researcher has been also appointed to the section chief of physical education since 2004. Some problems on teaching martial arts included the complexity of motion of extremities and the grasp of space and accuracy, and so much more had to be taken into accounts and handled. Moreover, these teachers have a class of twenty to thirty students encountered difficulties

(C) 2019 by the authors; licensee Modestum Ltd., UK. This article is an open access article distributed under the terms and conditions of the Creative Commons Attribution License (http://creativecommons.org/licenses/by/4.0/). \fweng@wfu.edu.tw gfweng3@gmail.com (*Correspondence) $\square$ hhj@wfu.edu.tw $\square$ ryang@miners.utep.edu \gfweng@gmail.com 


\section{Contribution of this paper to the literature}

- The multimedia teaching material is designed by experts to examine if it works well on teaching Taekwondo aerobic.

- Both students' learning attitude and learning styles are examined. The material can promote students' learning attitude.

- While employing the multimedia teaching, the teacher shouldn't simply presume the rich content. Learning styles are suggested to be considered and enhance the learning achievement.

in increasing the recognition of every skills of motions. These students got used to the traditional teaching mode with simply self-demonstration of motions and going around instruction (Wei \&Chen, 2013).

Meanwhile, the students without the foundation of Taekwondo athletics also did encounter difficulties in learning the quality, strength, and a set pattern of Taekwondo. In shortly several weeks of curriculum of physical education, not to mention that county Yunlin was the only one that furthered Taekwondo Aerobic as physical education. It was not even mentioned in the curriculum of nine year's consistent education. Therefore, the learning style of the students in Taekwondo Aerobic unit was always hardly good under the situation. These students had difficulties to learn and no intention to learn as well. This research aimed to improve the learning outcomes of Taekwondo athletics through the understanding of the learning style of students.

Many researches indicated that multimedia curriculum would be able to effectively increase the learning style of students. Thus, in this study we produced the digital teaching material of Taekwondo Aerobic to digitalize the teaching material of Taekwondo Aerobic athletics. We also provided the key and iterative observations of the motions to shorten the learning periods of time. A material was established with new teaching mode of martial arts athletics. It provided a set of digital teaching material for self-paced learning to promote the recognition of skills of motions of Taekwondo Aerobic.

Some researchers also indicated that learning attitude was also affected by learning style. For example, Felder and Silverman (Felder \& Silverman, 1988) mentioned that each student had his learning style which significantly affected his learning outcomes. The main purpose of this study was to investigate how multimedia teaching material affected the learning style.

\section{RELATED STUDIES}

This study mainly investigated the effect of multimedia teaching material instruction of Taekwondo Aerobic. Moreover, the significance of different learning attitude of different learning style is also discussed. This section consisted of three subsections: the application of integrated multimedia instruction of physical education, the theory of learning style, and learning attitude.

\section{Application of Integrated Multimedia Instruction of Physical Education}

The advancement of IT (information technology) made integrated IT instruction a common trend of teaching in education, which not only changed the social structure but also became a key of reform of education. Even the nine years' consistent curriculum stressed on the learning tools by employing computer as an aid so as to explore the learning in every domain (MOE, 2008). Most application type of IT in health and physical education have been the teaching. Some researchers investigated the teaching effects of physical education curriculum by using iPad as integrated tools (Lin, Hung, \&Young, 2014), the results indicated that by employing iPad-assisted instruction, it is helpful to promote the learning outcomes of skills of badminton not only from the objective data of evaluation of expert but also from the subjective data of questionnaire self-evaluation of conscious learning outcomes according to the self-paced learning. Another some researchers focused on the subject in multimedia teaching of weight training curriculum (Chen, 2015) and the results indicated that by employing network multimedia-assisted instruction, the expected effect of three objectives, namely, the cultivation of habit of athletics in the weight training, the increase of revenue of athletics arena, and the improvement of ache of low back were achieved and another three objectives, namely, the physical fitness and fundamental ability of body, the satisfiability of curriculum, and the hits rate of network were also achieved. Compared to traditional instruction, the network-assisted instruction had certainly the functionality and convenience in the learning. In summary, we found the research results as follows:

Integrating IT with the teaching of physical education may adjust the progressing time of curriculum and the learners may enhance the lack of learning after the school by network learning to increase the learning outcomes and reach the effect of tailored teaching. Our research results indicated that Integrating IT with the teaching of physical education certainly affected teaching effect and most of the affection were positive, especially the affection 
of learning of skills was most significant. Our research results also indicated that most students had positive view on integrating IT with the teaching of health and physical education and had increased the effect of learning attitude.

\section{Learning Style}

Every student has their learning style no matter how their intelligence or academic achievement are. Many researches also indicated that learning style affected learning mode. A research examining college students' preferred style of learning. His results showed that the genders and the subject affected the preferred learning style. (Chen, Jones, \& Xu, 2018). Federico (2000) indicated that the main criteria of adaptive teaching was that there was no teaching strategy was the best for all the students and only the teaching activities and strategy suitable for the difference of individual would be able to obtain the best learning outcomes. Learning style was one of the differences of individual. Since long ago, the related researches on the affection of learning outcomes by the difference of individual have been one of important research issues in the field of phycology of recognition (Ayersman \& von Monden, 1995). For medical students, learning style also influenced his/her academic performance (Nichols and Edmondson, 2016).

Learning style has been discussed in the e-learning system to discuss the problems and opportunities (Truong, 2016). Learning styles also have been applied to classify students by vary their ability of academic achievement. The results suggested that adapting student assessment based on learning styles may provide a more reliable measure of their ability (Adkins \& Guerreiro, 2017).

Many scholars thought that learning style can be categorized in many ways. Different research methods and types of categorization were employed, in which the characteristics of orientation of definition and key elucidations were stressed on differently by learning style. For example, Honey and Mumford (Honey \& Mumford, 1986) developed the LSQ (Learning Style Questionnaires) to determine the type of learning style which was categorized into four types of activist, reflector, theorist, and pragmatist. Kolb $(1976,1984)$ proposed the ELT (Experiential Learning Theory) which integrated the pragmatism by Deway, social phycology by Lewin, and recognition by Piaget and in which the learning style was categorized into four types of consolidate experience, thinking of observation, abstract concept, and active verification. An article reviews the application of Kolb learning Style Inventory (LSI) in the examination of learning styles among nursing students. Their result showed the positives to LSI (DeCoux, 2016).

The progress of Taekwondo learning started from the practical mimic learning of fundamental single motion through the decomposition of a set pattern in Ta Chi Eight Chapters, then the introspection of the content of a set pattern, which increased the ability of perception of intrinsic self and environment, in addition to the change of physiology, and finally the iterative excises of motions of a set pattern to realize the thoughtfulness of Taekwondo athletics and to facilitate the conversion of experience and the daily life of Taekwondo athletics. Therefore, this study analyzed the learning style of students based on the cyclic theory of experience learning proposed by Kolb.

\section{Learning Attitude}

Attitude refers to the evaluation of a specific target and behavior of individual in the environment and is also an obtained inclination after learning and a consistent behavior due to the incurring feel and opinion after the recognition and evaluation of events and objects (Pruet, Ang, \& Farzin, 2016). The targets of attitude are multilateral including people, events, objects, groups, systems, and concepts on behalf of consolidate events and objects. Attitude usually consists of three aspects of recognition, emotion, and action which results in difference of attitude of individual due to the different strength and scope or the content of each aspect.

Chang (2001) indicated that the meaning of attitude consisted of three aspects, namely, aspect of recognition, aspect of emotion, and aspect of action. The aspect of recognition was the psychological progress of understanding and recognition of people, events, and objects, which was created via conscious activities of individual. The aspect of emotion was the specific attitude of certain target of individual in all emotions and moods, especially when the evaluation of the specific attitude of the target was positive or negative. The aspect of action was the specific attitude of certain target of individual presented by the inclination of action. Lin and Chiu (2003) also indicated that individual evaluated differently in the three aspects of learning attitude, i.e., aspect of recognition, aspect of emotion, and behavioral aspects, on the curriculum of physical education implemented by the school, which was used to determine the response in listing the items of questionnaire for learning attitude of physical education. Chen and Yu (2010) investigated the learning attitude and satisfiability of physical education in high school and the results indicated the scores of learning attitude were the highest in the aspect of intentions and actions and the second of recognition and emotion. Also, the satisfiability of learning of physical education affected the learning attitude in forward direction. Huang (2013) also indicated that the difference between the three aspects of 
recognition, emotion, and behaviors of learning attitude and the satisfiability, relation, and self-confidence, reached the significance level in different educational system.

Learning technology is continuous adopting in every sectors. In education field, to encourage children to participate physical activity is essential for elementary education. The usage of technology would bring new environment to attract children to participate. Children live in urban or rural has different resources and it makes them different experience (Pruet, Ang, \& Farzin, 2016). The learning attitude of physical education was very important and it might directly or indirectly affect the intention of persistence in participating in the athletics. Therefore, cultivating correct learning attitude of physical education was unneglectable in fostering good habit of athletics.

In summary, the learning attitude was a key factor which affected the learning outcomes. The teachers could then bring teaching into full play only if the teachers understood the learning attitude, compiled and designed the right teaching material and teaching mode and enabled the students to yield twice the result with half the effort in learning. As an educator, the teachers should pay attention to the difference of individual, grasp the learning style, and aim to promote good learning attitude. We then intended to understand the learning style so as to various learning attitude of student through different teaching modes with different teaching approaches.

\section{RESEARCH METHOD}

This study adopted quasi experiment as the participants were not randomly assigned. After conducting the quasi-experiments treatments, a questionnaire survey was conducted to analysis the effects. We investigated the effect of learning attitude on different learning style by multimedia and traditional instruction of Taekwondo Aerobic. Two independent variables were teaching mode and learning style. Teaching modes were designed into two groups. They are multimedia mode and traditional one. Learning styles were categorized into four types based on Kolb's learning style. They were diffusion, assimilation, convergence and adaption. The dependent variable was learning attitude which was categorized into three aspects of recognition, emotion, and behaviors. The learning styles were categorized based on Kolb's learning concept and theoretical frameworks. The questionnaires consist of 30 items.

In this study, we designed both experimental and controlled group in which both teachers, of the sample physical education classes. Both teachers have teaching experience and similar educational and working background. They have same teaching environment and same ability to grasp the learning atmosphere and teaching time. In the experimental group, computer and large screen display projector were employed to present teaching material in preparatory classroom and in controlled group. The motions were demonstrated by the teacher in outdoor shade. The content of teaching material was Tai Chi Eight Chapters (chapter 1 through 8) of Taekwondo Aerobic, which was edited with dynamism of music. The entire teaching time of the curriculum for experimental class was 270 minutes spanning over 3 weeks. Per class has 45 minutes for 6 hours.

The measuring tools were the questionnaires for learning style and learning attitude. The learning style were presented by the scores on the learning attitude of recognition, emotion, and behaviors. It was calculated based on Likert's five-scale measurement. The population was made of some students from $7^{\text {th }}$ and $8^{\text {th }}$ grades of a junior high school. Most students were from the elementary schools in Yunlin county. With convenience of sampling, students were from three classes of $7^{\text {th }}$ and $8^{\text {th }}$ grades (marked as A, B, and C). They were taught by the researcher in the experimental group to conduct the integrated multimedia teaching demonstration (aka. digital teaching material instruction). The others were from another class of $7^{\text {th }}$ grade (marked as D). They were taught by the wellexperienced teacher of physical education in the controlled group, who was also appointed as the convener of health and physical education, to conduct the traditional teaching demonstration.

The hypotheses in this study include:

- learning modes have significant effects on learning attitude

- learning styles have significant effects on learning attitude

The population was 105, consisted of 78 of experimental group (multimedia teaching demonstration) and 27 of controlled group (traditional teaching demonstration). For the convenience of this study, we conducted the experiment on three classes which were assigned to one of our researchers. Two classes were designed to experimental group and total number of students were 78. The third class was designed as controlled group with only 27 students. After the collection of survey, the valid population was 75 and 26 , respectively, due to the absence of students and void of questionnaires.

\section{RESEARCH RESULTS}

Data were tested the normality firstly. The result showed that the data were all normality distribution as it passed the criteria of $p$-value $>.05$. The variables were then tested the reliability and validity. The relationships 
Table 1. Factor loading and reliability on learning attitude

\begin{tabular}{|c|c|c|c|}
\hline \multirow{2}{*}{ Item NO. } & \multicolumn{3}{|c|}{ Factor loading } \\
\hline & behaviors & recognition & emotion \\
\hline 1 & .909 & & \\
\hline 2 & .893 & & \\
\hline 4 & .873 & & \\
\hline 6 & .796 & & \\
\hline 8 & & .775 & \\
\hline 9 & & .682 & \\
\hline 10 & & .677 & \\
\hline 12 & & .644 & \\
\hline 17 & & .609 & \\
\hline 20 & & .579 & \\
\hline 22 & & & .807 \\
\hline 23 & & & .700 \\
\hline 28 & & & .675 \\
\hline 29 & & & .671 \\
\hline 30 & & & .616 \\
\hline Eigen value & 7.058 & 1.636 & 1.143 \\
\hline Cronbach's alpha & .956 & .832 & .813 \\
\hline
\end{tabular}

Table 2. t-test on teaching mode to learning attitude

\begin{tabular}{lccccc}
\hline \multirow{2}{*}{ Learning Attitude } & \multicolumn{3}{c}{ Mean } & \multirow{2}{*}{ t-value } & \multirow{2}{*}{ p-value } \\
\cline { 2 - 3 } & Controlled Group & Experimental Group & & $.000^{\star}$ \\
\hline aspect of recognition & -0.91 & 0.31 & -6.448 & $.000^{\star}$ \\
\hline aspect of emotion & -1.04 & 0.36 & -7.847 & $.000^{\star}$ \\
\hline Behavioral Aspect & -0.63 & 0.22 & -4.051 & \\
\hline
\end{tabular}

were tested by t-test and One-way ANOVA, in which the criteria were based on significance level ( $p$-value) if $p<$ 0.05 . Scheffé's method was also employed to understand the difference of characteristic of different samples among the groups if it existed. There were 101 valid samples with 26 in controlled group and 75 in experimental group.

\section{Validity and Reliability Test}

The coefficient of KMO sampling fit of learning attitude was 0.886 which was greater than 0.8. The Bartlett's testing statistics p-value was 0.00 which was less than 0.05 . It was eligible to conduct the factor analysis. The factor analysis divided the questionnaire for learning attitude into three aspects of recognition, emotion, and behaviors and deleted the items of questionnaire. They were items $3,5,7,11,13,14,15,16,18,19,21,24,25,26$, and 27, in which the factor load value was less than 0.5 . The reliabilities of three aspects of behaviors, emotion, and recognition for different learning styles were $.956, .832$, and .813 , respectively, which were very high reliability. It shows in Table 1. The further analysis of the results was conducted.

\section{Hypothesis Testing between Learning Attitude and Style}

\section{T-test of different teaching mode vs. learning attitude}

Comparing the teaching mode with learning attitude by employing t-test of independent samples, the testers of different teaching mode indicated significant difference (i.e., $\mathrm{p}<0.05$ ) in all three aspects of emotion, recognition, and behaviors of learning attitude as shown in Table 2. Therefore, the learning attitude of students in the experimental group was better than in the controlled group. The students in experimental group would be able to view the motions demonstrated on large screen by projector. The teacher also gave the feedbacks to the students whose motions needed to be improved or corrected. It would shorten the learning time and also be more efficient.

\section{Single-factor variance analysis of categorized BMI vs. learning attitude}

For both the experimental and controlled group, comparing the categorized BMI with learning attitude by employing one-way ANOVA, the p-value of the testers of different BMI was $.038(\mathrm{p}<0.05)$ in the aspect of recognition and $.014(\mathrm{p}<0.05)$ in the aspect of emotion in the controlled group, which indicated that both had significant difference. After the Multiple Comparisons (Post Hoc Testing,) we found that the categorized BMI 
Normal had more positive thinking in the aspect of recognition than other aspects. The categorized BMI Overweigh also had more significant difference in the aspect of emotion than other aspects.

\section{Single-factor variance analysis of categorized physical fitness vs. learning attitude}

For both experimental and controlled group, comparing the categorized physical fitness with learning attitude by employing one-way ANOVA, the testers of both groups showed no significant difference which indicated that the physical fitness had nothing to do with the learning attitude.

\section{Single-factor variance analysis of learning style vs. learning attitude}

For both experimental and controlled group, comparing the learning style with learning attitude by employing one-way ANOVA, the p-value of the testers of different learning style and learning attitude were .00 in the three aspects in the experimental group which all indicated significant difference. On the other hand, the controlled group were shown non-significant by employing Scheffé's method of Post Hoc Testing.

Aspect of Recognition: Three sets of learning styles Diffusion and Adaption, Convergence and Adaption and Assimilation and Adaption all had significant difference. The result discussed above that the learning style Adaption had more significant difference in the aspect of recognition than other aspects of learning style. It inferred that the students of learning style Adaption were likely to actively verify and consolidate experience. They also intuitively accomplish project or mission by try and error. These approaches could help students obtain new experience and thus adjusted self-thinking and accepted new type of curriculum activities.

Aspect of Emotion: Both sets of learning styles Adaption and Diffusion and Assimilation and Diffusion had significant difference. The result discussed above indicated that the learning style Diffusion had more significant difference than other learning styles. It inferred that the students of learning style Diffusion were likely to consolidate experience and think the observation. To have stronger emotion and ability of observation, they like to observe people and events to obtain knowledge and thus to blend into personal emotion to accept. They thus like the new teaching mode.

Behavioral Aspects: Three sets of learning styles Diffusion and Assimilation, Adaption and Assimilation, and Convergence and Assimilation all had significance difference as shown in Table 3. The result shown above also indicated that the students of learning styles Assimilation had more significant difference than other three aspects in the behavioral aspects of learning attitude. It inferred that the students of the learning style Assimilation were likely to think the observation and abstract concepts. To have stronger abilities of inductive reasoning and creation of theoretical framework, they were able to observe and induct the information to elucidate the assimilation and propose the complete interpretation. They then actively observe teacher's motion and constantly stay tuned the curriculum activities after the school. 
Table 3. Multiple Comparisons (Post Hoc Testing) of Learning Style vs. Learning Attitude in Experimental Group

\begin{tabular}{|c|c|c|c|}
\hline Dependent Variable & (I) Style & (J) Style & Significance Level \\
\hline \multirow{12}{*}{$\begin{array}{l}\text { Aspect of } \\
\text { Recognition }\end{array}$} & \multirow{3}{*}{ Diffusion } & Adaption & .000 \\
\hline & & Convergence & .965 \\
\hline & & Assimilation & .989 \\
\hline & \multirow{3}{*}{ Adaption } & Diffusion & .000 \\
\hline & & Convergence & .049 \\
\hline & & Assimilation & .000 \\
\hline & \multirow{3}{*}{ Convergence } & Diffusion & .965 \\
\hline & & Adaption & .049 \\
\hline & & Assimilation & .989 \\
\hline & \multirow{3}{*}{ Assimilation } & Diffusion & .989 \\
\hline & & Adaption & .000 \\
\hline & & Convergence & .989 \\
\hline \multirow{12}{*}{$\begin{array}{l}\text { Aspect of } \\
\text { Emotion }\end{array}$} & \multirow{3}{*}{ Diffusion } & Adaption & .001 \\
\hline & & Convergence & .999 \\
\hline & & Assimilation & .014 \\
\hline & \multirow{3}{*}{ Adaption } & Diffusion & .001 \\
\hline & & Convergence & .099 \\
\hline & & Assimilation & .730 \\
\hline & \multirow{3}{*}{ Convergence } & Diffusion & .999 \\
\hline & & Adaption & .099 \\
\hline & & Assimilation & .272 \\
\hline & \multirow{3}{*}{ Assimilation } & Diffusion & .014 \\
\hline & & Adaption & .730 \\
\hline & & Convergence & .272 \\
\hline \multirow{12}{*}{ Behavioral Aspects } & \multirow{3}{*}{ Diffusion } & Adaption & .999 \\
\hline & & Convergence & .790 \\
\hline & & Assimilation & .000 \\
\hline & \multirow{3}{*}{ Adaption } & Diffusion & .999 \\
\hline & & Convergence & .740 \\
\hline & & Assimilation & .000 \\
\hline & \multirow{3}{*}{ Convergence } & Diffusion & .790 \\
\hline & & Adaption & .740 \\
\hline & & Assimilation & .004 \\
\hline & \multirow{3}{*}{ Assimilation } & Diffusion & .000 \\
\hline & & Adaption & .000 \\
\hline & & Convergence & .004 \\
\hline
\end{tabular}

\section{DISCUSSION}

As showed above, the results show that multimedia-based teaching style enhances students' learning attitude. Using multimedia teaching approach has generally better effects on students' learning attitude. However, different learning styles has specific consequence. The followings discuss four aspects on multimedia teaching mode, learning attitude, and learning style.

\section{Multimedia Teaching Mode would be Better to Promote the Learning Attitude in the Teaching Activities of Physical Education}

Taekwondo is a discipline of martial arts athletics focused on fundamentals and divided into four categories: basic motions, pattern, pair exercise, and defeat. The beginners must start from the simplicity to complexity and from ease to difficulty, following the prescribed order. County Yunlin in Taiwan furthered the martial arts athletics which was mandatory for students to learn. For the beginners of Taekwondo, the problems the teachers encountered were the consideration of complexities of motions and the solution and grasp of space and preciseness. By employing the integrated multimedia teaching material instruction, the videos would be able to be produced according to the requirements of curriculum. These motions were decomposed and the stay time of videos were monitored. The teachers would be able to give feedbacks to students based on the learning status in order to shorten the learning time of Taekwondo Aerobic. Students would also be able to learn better, be more self-confident. They thus significantly promoted the learning attitude. Suggested that county Yunlin produce related teaching videos to 
shorten the learning time and increase the learning outcomes. To alleviate the burden imposed on the teachers, this teaching mode could fulfil the martial arts athletics.

The averages of learning attitude of experimental group were great than controlled group. It shows that the teacher easily increased the learning intention and attitude by employing multimedia teaching mode. By adopting integrated multimedia teaching, the video would be able to be produced according to the requirement of courses. The decomposition of motion and the grasp of the stay time on the video could be paused at any time. The teacher then would be able to give feedbacks to the students depending on the learning status. This approach would shorten the learning time of Taekwondo Aerobic and improve the learning outcomes, self-confidence, and learning style.

\section{The Students of Different Learning Style had Significant Difference in the Learning Attitude by Employing Multimedia Teaching Mode}

The learning style affected the learning preference and further affected the learning outcomes and attitude. Therefore, the teachers should change the content of courses and teaching mode according to the objective of course. It would increase the learning motives, learning outcomes, and learning attitude to benefit all categories of learning style. This study indicated that the students of learning style Adaption in the aspect of recognition of learning attitude had more significant difference than three other learning styles. The students of learning style Diffusion had more significant difference than the learning styles Adaption and Assimilation. Students of learning style Assimilation had more significant difference than other three learning styles. Therefore, each student was a unique individual whose learning outcomes and attitude were not the same. The teachers thus, as an educator, should give an adaptive and tailored teaching based on the difference of individual.

Based on the results above, the teachers should provide the right teaching material and exercise multiple teaching mode to achieve the objective of teaching. In the primary period of time, the teachers blended multimedia teaching material into the teaching activities of Taekwondo Aerobic. Students felt new and interesting and so were attracted. However, how to keep the same learning interest in the teaching activities of successive six hours was also the factor concerned. Thus, exercising multimedia teaching material instruction should match the learning requirements and interest in order to achieve the teaching objective.

\section{The Learning Attitude was Independent of Sex and Categorized Physical Fitness}

The learning attitude of Taekwondo athletics showed no difference because of the difference of sex. The learning attitude also showed no change because of the difference of teaching mode of teacher. The variable of score of students' physical fitness was also independent with the attitude. It presents that learning attitude of Taekwondo could be promoted without the limitation of students' physical scores.

\section{The Learning Attitude of Taekwondo Aerobic was Affected by Categorized BMI}

In the investigation of Body Mass Index (BMI) and learning attitude, we found that the testers of categorized BMI Normal in the controlled group BMI normal showed more positive thinking than the other categorized BMI in the aspect of recognition. The testers of categorized BMI Overweigh showed more significant difference than other categorized BMI in the aspect of emotion. These students with overweight could feel inferiority on doing exercise. The multimedia material would be helpful for them to practice at home. It would give them a chance to try to duo exercise step by step. Moreover, teachers would encourage them to practice more even in class or at home.

\section{CONCLUSIONS}

The main purpose of this study was to investigate the impact of Taekwondo Aerobic teaching material on the learning attitude in Yunlin county. There are 101 valid questionnaires. Students' learning style is an essential variable on discussing the martial arts athletics. This research investigated the impact of learning style and teaching mode on learning style. The t-test and ANOVA are used to analysis the data. The results are concluded in four aspects. First, multimedia teaching mode would be better to promote the learning attitude. Secondly, different learning style has significant difference on teaching mode. Thirdly, learning attitude was independent of sex and categorized physical fitness. Last of all, learning attitude of Taekwondo Aerobic was affected by categorized BMI. Multimedia teaching material thoroughly has positive effect on learning the Taekwondo Aerobic.

Although the multimedia teaching material instruction has positive effect on teaching exercise, it couldn't substitute the interaction between teacher and students in the traditional teaching. Especially, in the learning of physical education, the students must set an example by personally taking part in doing the correct postures and 
motions and in the learning process. Students often encountered the difficulty and information ambiguity which needed the immediate response and instruction. Therefore, while employing the computer multimedia teaching, the teacher shouldn't simply presume the rich content. On time feedbacks to the students are still benefit to learn. Using the multimedia accompanied with the traditional teaching approach both to increase teaching effects.

\section{REFERENCES}

Adkins, D., \& Guerreiro, M. (2017). Learning styles: Considerations for technology enhanced item design. British journal of educational technology. https:/ / doi.org/10.1111/bjet.12556

Ayersman, D., \& von Minden, A. (1995). Individual differences, computers, and instruction, Computers in Human Behavior, 11(3-4), 371-390. https:/ / doi.org/10.1016/0747-5632(95)80005-S

Chang, C.-H. (2001). Phycology of Education. Taiwan: Tung Hua Book Co., Ltd.

Chen, C., Jones, K. T., \& Xu, S. (2018). The Association between Students' Style of Learning Preferences, Social Presence, Collaborative Learning and Learning Outcomes, Journal of Educators Online, 15(1). https://doi.org/10.9743/JEO2018.15.1.3

Chen, L.-C., \& Yu, J.-M. (2010). A Study of Relationship between Learning Satisfiability and Learning Style of Physical Education of Students in High School, Northern Taiwan. Journal of Physical Education, Health, and Leisure, National Chiayi University, 9(3), 149-161.

Chen, M.-K. (2015). Project of Teaching Enhancement-Study of Weight Training Course through Multimedia. Physical Education Journal, 14, 127-138.

DeCoux, Valerie M. (2016). Kolb's Learning Style Inventory: A review of its applications in nursing research. Journal of Nursing Education, 29(5, 202-207.

Federico, P. A. (2000). Learning styles and student attitude toward various aspects of network-based instruction. Computers in Human Behavior, 16, 359-379. https:/ / doi.org/10.1016/S0747-5632(00)00021-2

Felder, R., \& Silverman, L. (1988). Learning and teaching style in engineering education. Engineering education, 78(7), 674-681.

Honey, P., \& Mumford, A. (1986). The manual of learning styles. Linden Avenue, Maidenhead: Peter Honey.

Huang, W.-P. (2013). The Related Researches of Attitude and Learning Motive of Physical Education Curriculum Participated by College Students. Journal of Physical Education, Health, and Leisure, 12(2), 26-39.

Kolb, D. A. (1976). Learning style technical manual. Boston: Mcber and Company.

Kolb, D. A. (1984). Experiential Learning: Experience as the Source of Learning and Development. Englewood Cliffs, N.J.: Prentice-Hall, Inc.

Lin, K.-C., Hung, H.-C., \& Young, S.-C. (2014). The Effectiveness of Adopting Tablets Pc in Physical Education of Badminton Skill. Physical Education Journal, 47(3), 437-449.

Lin, P.-Y., Lin, C., \& Chiu, C.-S. (2003). A Pilot Study to Develop a Primary and High School Student Attitude Scale Toward Physical Education. Sports \& Exercise Research, 5(1), 11- 25.

MOE. (2008). Information Education of Elementary and Junior High School White Paper. Taiwan.

Nichols, C. T., \& Edmondson, A. C. (2016). Examination of the Roles of Learning Style and Learning Strategy on the Academic Performance of First Year Medical Students. The FASEB journal, 30(1).

Pruet, P., Ang, C. S., \& Farzin, D. (2016). Understanding tablet computer usage among primary school students in underdeveloped areas: Students' technology experience, learning styles and attitudes. Computers in Human Behavior, 55(B), 1131-1144.

Truong, H. M. (2016). Integrating learning styles and adaptive e-learning system: Current developments, problems and opportunities. Computers in Human Behavior, 55(B), 1185-1193.

Wei, Y.-F., \& Chen, B.-I. (2013). Research of National Sport Venues' Operational Strategies to the Trend of Aging Population with Declining Birthrate. Quarterly of Chinese Physical Education, 27(2), 113-117.

\section{http://www.ejmste.com}

